- Data Description Article •

\title{
CAS FGOALS-f3-L Model Datasets for CMIP6 Historical Atmospheric Model Intercomparison Project Simulation
}

\author{
Bian $\mathrm{HE}^{1,2,3}$, Qing BAO*1,2 , Xiaocong WANG ${ }^{1,2}$, Linjiong ZHOU ${ }^{4}$, Xiaofei WU ${ }^{5}$, Yimin LIU ${ }^{1,2,3}$, \\ Guoxiong WU ${ }^{1,2,3}$, Kangjun $\mathrm{CHEN}^{1}$, Sicheng $\mathrm{HE}^{6}$, Wenting $\mathrm{HU}^{1,3}$, Jiandong $\mathrm{LI}^{1,3}$, Jinxiao $\mathrm{LI}^{1,3}$, \\ Guokui NIAN $^{1,3}$, Lei WANG ${ }^{1,3}$, Jing YANG ${ }^{6}$, Minghua ZHANG ${ }^{1}$, and Xiaoqi ZHANG ${ }^{7,1}$ \\ ${ }^{1}$ State Key Laboratory of Numerical Modeling for Atmospheric Sciences and Geophysical Fluid Dynamics, \\ Institute of Atmospheric Physics, Chinese Academy of Sciences, Beijing 100029, China \\ ${ }^{2}$ Chinese Academy of Sciences Center for Excellence in Tibetan Plateau Earth Sciences, Beijing 100101, China \\ ${ }^{3}$ University of Chinese Academy of Sciences, Beijing 100049, China \\ ${ }^{4}$ Geophysical Fluid Dynamics Laboratory, Princeton, NJ 08540-6649, USA \\ ${ }^{5}$ School of Atmospheric Sciences/Plateau Atmosphere and Environment Key Laboratory of Sichuan Province, \\ Chengdu University of Information Technology, Chengdu 610225, China \\ ${ }^{6}$ State Key Laboratory of Earth Surface Processes and Resource Ecology/Academy of Disaster Reduction and Emergency \\ Management Ministry of Civil Affairs and Ministry of Education, Faculty of Geographical Science, \\ Beijing Normal University, Beijing 100875, China \\ ${ }^{7}$ School of Atmospheric Sciences, Nanjing University of Information Science and Technology, Nanjing 210044, China
}

(Received 9 February 2019; revised 30 March 2019; accepted 19 April 2019)

\begin{abstract}
The outputs of the Chinese Academy of Sciences (CAS) Flexible Global Ocean-Atmosphere-Land System (FGOALSf3-L) model for the baseline experiment of the Atmospheric Model Intercomparison Project simulation in the Diagnostic, Evaluation and Characterization of Klima common experiments of phase 6 of the Coupled Model Intercomparison Project (CMIP6) are described in this paper. The CAS FGOALS-f3-L model, experiment settings, and outputs are all given. In total, there are three ensemble experiments over the period 1979-2014, which are performed with different initial states. The model outputs contain a total of 37 variables and include the required three-hourly mean, six-hourly transient, daily and monthly mean datasets. The baseline performances of the model are validated at different time scales. The preliminary evaluation suggests that the CAS FGOALS-f3-L model can capture the basic patterns of atmospheric circulation and precipitation well, including the propagation of the Madden-Julian Oscillation, activities of tropical cyclones, and the characterization of extreme precipitation. These datasets contribute to the benchmark of current model behaviors for the desired continuity of CMIP.
\end{abstract}

Key words: CMIP6, AMIP, FGOALS-f3-L, MJO, tropical cyclone, extreme precipitation

Citation: He, B., and Coauthors, 2019: CAS FGOALS-f3-L model datasets for CMIP6 historical Atmospheric Model Intercomparison Project simulation. Adv. Atmos. Sci., 36(8), 771-778, https://doi.org/10.1007/s00376-019-9027-8.

\section{Article Highlights:}

- AMIP simulation datasets produced by CAS FGOALS-f3-L covering 1979 to 2014 are described.

- The dataset contains three ensemble members with different initial states by the time lag method.

- The model outputs contain a total of 37 variables and include the three-hourly mean, six-hourly transient, daily and monthly mean datasets.

\section{Introduction}

The Coupled Model Intercomparison Project (CMIP) has

\footnotetext{
* Corresponding author: Qing BAO

Email: baoqing@mail.iap.ac.cn
}

been an essential platform to better understand past, present and future climate change arising from natural, unforced variability or in response to changes in radiative forcings in a multimodel context (Eyring et al., 2016). In recent years, phase 6 of CMIP (CMIP6) was launched with a new and more federated structure that has many updates to the experiments 
in CMIP5. The experiments in CMIP6 are divided into two groups. One is the Diagnostic, Evaluation and Characterization of Klima (DECK) and CMIP6 historical simulations. The other is the Endorsed Model Intercomparison Projects (MIPs). The DECK and CMIP historical simulations (1850near present) group, maintains continuity and helps to retain the basic document characteristics of models across different phases of CMIP. The Endorsed MIPs group addresses a large range of specific questions and fills the scientific gaps in previous CMIP phases.

The Atmospheric Model Intercomparison Project (AMIP) simulation (Gates, 1992; Gates et al., 1999) is the first experiment designed in DECK. The AMIP experiment has been routinely carried out by modeling centers to evaluate their atmospheric models for its simplicity in methodology over the last three decades. The aim of the simulation is to analyze and evaluate the atmosphere and land in the climate system when they are constrained by observed sea surface temperatures (SSTs) and sea-ice concentrations. The systematic model errors can be identified by comparing the simulations to the observed atmosphere and land states in statistical ways. The simulation can also be useful for understanding climate variability and many aspects of historical climate changes for the climate science community.

The low-resolution version of the Chinese Academy of Sciences (CAS) Flexible Global Ocean-Atmosphere-Land System model, finite-volume version 3 (CAS FGOALS-f3-L) climate system model was developed at the State Key Laboratory of Numerical Modeling for Atmospheric Sciences and Geophysical Fluid Dynamics (LASG), Institute of Atmospheric Physics (IAP), CAS (Bao et al., 2019). The model completed the AMIP simulations in late 2018, and the model outputs were prepared for release after a series of postprocesses. To provide a description of the AMIP model outputs and the relevant essential model configurations and experimental methods for a variety of users, we document detailed descriptions of the AMIP simulation by CAS FGOALS-f3$\mathrm{L}$ in this paper. Section 2 presents the model description and experimental design. Section 3 addresses the technical validation of the outputs from the CAS FGOALS-f3-L experiments. Section 4 provides usage notes.

\section{Model and experiments}

\subsection{Introduction to the model}

CAS FGOALS-f3-L is composed of five components: version 2.2 of the Finite-volume Atmospheric Model (FAMIL) (Zhou et al., 2015; Bao et al., 2019; Li et al., 2019), which is the new generation atmospheric general circulation model of the Spectral Atmosphere Model of LASG (SAMIL) (Wu et al., 1996; Bao et al., 2010, 2013) (their main differences are shown in Table 1); version 3 of the LASG/IAP Climate system Ocean Model (LICOM3) (Liu et al., 2012); version 4.0 of the Community Land Model (CLM4) (Oleson et al., 2010); version 4 of the Los Alamos sea ice model (CICE4) (Hunke and Lipscomb, 2010); and version 7 of the coupled module from the National Center for Atmospheric Research (NCAR) (http://www.cesm.ucar.edu/ models/cesm1.0/cpl7/), which is used to exchange the fluxes among these components.

The atmospheric component, FAMIL, uses a finitevolume dynamical core (Lin, 2004) on a cubed-sphere grid (Putman and Lin, 2007), with six tiles across the globe. In FAMIL, each tile contains 96 grid cells (C96). Globally, the longitudes along the equator are divided into 384 grid cells, and the latitudes are divided into 192 grid cells, which is approximately equal to a $1^{\circ}$ horizontal resolution. In the vertical direction, the model uses hybrid coordinates over 32 layers, and the model top is at $2.16 \mathrm{hPa}$. The main physical packages include a new moisture turbulence parameterization scheme for the boundary layer (Bretherton and Park, 2009), with shallow convection updated (Wang and Zhang, 2014). The Geophysical Fluid Dynamics Laboratory version of a single-moment six-category cloud microphysics scheme (Lin et al., 1983; Harris and Lin, 2014) is adopted to predict the bulk contents of water vapor, cloud water, cloud ice, rain, snow and graupel. For the cloud fraction diagnosis, the $\mathrm{Xu}$ and Randall (1996) scheme is used, which considers not only relative humidity but also the cloud mixing ratio, thus providing a more precise cloud fraction. A convection-resolving precipitation parameterization (C) 2017 FAMIL Development Team) is used where, in contrast to the conventional convective parameterization, convective and stratiform precipitation

Table 1. Model configuration differences between FAMIL and SAMIL.

\begin{tabular}{|c|c|c|}
\hline Model configuration & SAMIL & FAMIL \\
\hline Dynamic core & $\begin{array}{l}\text { Spectral on longitude-latitude grid (Wu et al., 1996; } \\
\text { Bao et al., 2010) }\end{array}$ & $\begin{array}{l}\text { Finite volume on a cubed-sphere grid (Lin, 2004; Put- } \\
\text { man and Lin, 2007; Zhou et al., 2015) }\end{array}$ \\
\hline Resolution & $\mathrm{R} 42\left(2.81^{\circ} \times 1.66^{\circ}\right), \mathrm{L} 26$ & $\begin{array}{l}\mathrm{C} 96\left(1^{\circ} \times 1^{\circ}\right), \mathrm{L} 32 \\
\mathrm{C} 384\left(0.25^{\circ} \times 0.25^{\circ}\right), \mathrm{L} 32\end{array}$ \\
\hline Radiation & SES (Edwards and Slingo, 1996; Sun and Rikus, 1999) & RRTMG (Clough et al., 2005) \\
\hline Convection & Mass-flux (Tiedtke, 1989; Nordeng, 1994) & $\begin{array}{l}\text { The Resolving Convective Precipitation (RCP), C) } \\
\text { 2017, FAMIL Development Team, all rights reserved }\end{array}$ \\
\hline Microphysics & None & $\begin{array}{l}\text { One-moment bulk (Lin et al., 1983; Harris and Lin, } \\
\text { 2014) }\end{array}$ \\
\hline Boundary Layer & Non-local (Holtslag and Boville, 1993) & $\begin{array}{l}\text { Moist turbulence parameterization (Bretherton and } \\
\text { Park, 2009) }\end{array}$ \\
\hline
\end{tabular}


Table 2. Experiment designs.

\begin{tabular}{|c|c|c|c|}
\hline Experiment_id & Variant_label & Integration time & Experiment design \\
\hline amip & r1i1p1f1 & 1970-2014 & $\begin{array}{l}\text { The model integration starts from } 1 \text { January } 1970 \text { with the SST and sea-ice con- } \\
\text { centration prescribed as the observed values. All the external forcings, including } \\
\text { greenhouse gases, solar irradiance, ozone and aerosols, are prescribed as their } \\
\text { historical values. The first nine integration years are recognized as the spin-up } \\
\text { time, and the outputs from } 1979 \text { to } 2014 \text { are provided for analysis. }\end{array}$ \\
\hline amip & r2i1p1f1 & 1971-2014 & $\begin{array}{l}\text { Same settings as in r1i1p1f1, but the model integrates from } 1 \text { January 1971, and the } \\
\text { first eight years are the spin-up time. }\end{array}$ \\
\hline amip & r3i1p1f1 & 1972-2014 & $\begin{array}{l}\text { Same settings as in rli1p1f1, but the model integrates from } 1 \text { January 1972, and the } \\
\text { first seven years are the spin-up time. }\end{array}$ \\
\hline
\end{tabular}

are calculated explicitly. The Rapid Radiative Transfer Model for GCMs (RRTMG) (Clough et al., 2005) was introduced into the model as the main radiation transfer, which utilizes the correlated $k$-distribution technique to efficiently calculate the irradiance and heating rate in 14 shortwave and 16 longwave spectral intervals. Finally, a gravity wave drag scheme is also used, based on Palmer et al. (1986).

\subsection{Experiments}

Following the design of the DECK AMIP experiments (Eyring et al., 2016), we conducted three simulations, as summarized in Table 2. In these experiments, the external forcings are prescribed as their monthly mean observation values, as recommended by the CMIP6 projects: the historical global mean greenhouse gas concentrations from Meinshausen et al. (2017); solar forcing from Matthes et al. (2017); historical ozone concentrations from http://blogs.reading.ac.uk/ccmi/ forcing-databases-in-support-of-cmip6/; and AMIP SST and Sea Ice Datasets from the program for Climate Model Diagnosis \& Intercomparison (PCMDI) at https://esgf-node.llnl. gov/projects/esgf-llnl/. The aerosol mass concentrations are also prescribed and taken from the NCAR Community Atmosphere Model with Chemistry (CAM-Chem; Lamarque et al., 2012), there are five aerosol species including sulfates, sea salts, black carbon, organic carbon, and dust. The land use datasets are prescribed as their mean climate values (Hurtt et al., 2011).

As shown in Table 2, the experiment_id and variant_label are presented to identify each experiment and the corresponding outputs (Table 3 ). The time-lag method is used to realize the three perturbations that were identified by the variant_label: r1i1p1f1, r2i1p1f1, and r3i1p1f1. The characteristics in r1ilp1f1 denote the realization_index, initialization_index, physics_index, and forcing_index. The three ensemble simulations share the same model physics and forcing but differ due to their different integration start dates. The first experiment (r1ilp1f1) integrates from 1 January 1970. The first nine years are considered to be the spin-up period, and the model outputs from 1979 to 2014 are provided for public users. The second experiment (r2i1p1f1) is the same as r1ilp1f1, except that the integration start date is 1 January 1971. Similarly, the start date is 1 January 1972 in the third experiment (r3i1p1f1). All simulations are forced by the same varying external forcing during the observed time listed in the last paragraph.

\section{Model validation}

The model simulations have been evaluated on various time scales. Here, we show the validation at three temporal scales: monthly, daily, and six-hourly datasets (Table 3 ). The precipitation is one of the most important evaluation metrics. Here, we show the global distribution of climatological annual mean observed and simulated precipitation in Fig. 1. The observations from the Global Precipitation Climatology Project (GPCP) monthly precipitation dataset are used as the reference (Adler et al., 2003). It is clear that the model can capture the large-scale precipitation features well. Both the spatial pattern of precipitation along the ITCZ and SPCZ are well reproduced. Meanwhile, the model also suffers from systematic bias: the model simulates stronger precipitation in the tropical oceans and weaker precipitation over land than
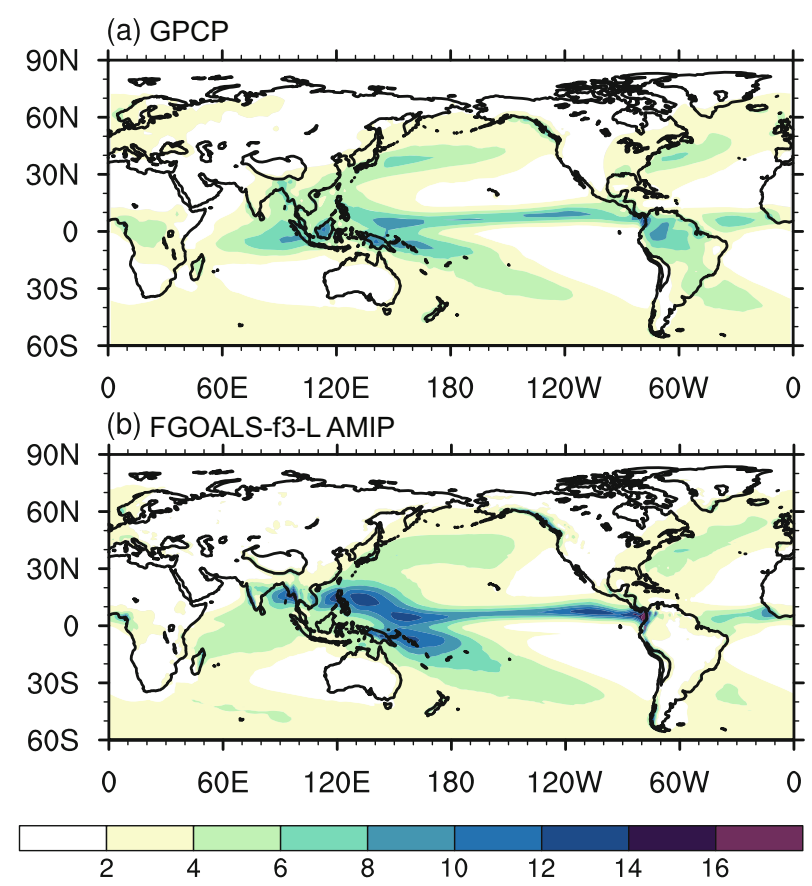

Fig. 1. Climatological (1979-2014) annual mean precipitation (units: $\mathrm{mm} \mathrm{d}^{-1}$ ) from (a) GPCP and (b) the mean of amip r1i1p1f1, r2i1p1f1, and r3i1p1f1. 
Table 3. CAS FGOALS-f3-L output variables prepared for CMIP6 DECK historical AMIP.

\begin{tabular}{|c|c|c|}
\hline $\begin{array}{l}\text { Output } \\
\text { name }\end{array}$ & Description & Frequency \\
\hline rlut & TOA outgoing longwave radiation & Monthly \\
\hline rsdt & TOA incident shortwave radiation & Monthly \\
\hline rsut & TOA outgoing shortwave radiation & Monthly \\
\hline rlutcs & $\begin{array}{l}\text { TOA outgoing clear-sky longwave } \\
\text { radiation }\end{array}$ & Monthly \\
\hline rsutcs & $\begin{array}{l}\text { TOA outgoing clear-sky shortwave } \\
\text { radiation }\end{array}$ & Monthly \\
\hline rlds & $\begin{array}{l}\text { Surface downwelling longwave ra- } \\
\text { diation }\end{array}$ & Monthly, $3 \mathrm{~h}$ \\
\hline rlus & $\begin{array}{l}\text { Surface upwelling longwave radia- } \\
\text { tion }\end{array}$ & Monthly, $3 \mathrm{~h}$ \\
\hline rsds & $\begin{array}{l}\text { Surface downwelling shortwave } \\
\text { radiation }\end{array}$ & Monthly, $3 \mathrm{~h}$ \\
\hline rsus & $\begin{array}{l}\text { Surface upwelling shortwave radi- } \\
\text { ation }\end{array}$ & Monthly, $3 \mathrm{~h}$ \\
\hline rldscs & $\begin{array}{l}\text { Surface downwelling clear-sky } \\
\text { longwave radiation }\end{array}$ & Monthly, $3 \mathrm{~h}$ \\
\hline rsdscs & $\begin{array}{l}\text { Surface downwelling clear-sky } \\
\text { shortwave radiation }\end{array}$ & Monthly, $3 \mathrm{~h}$ \\
\hline rsuscs & $\begin{array}{l}\text { Surface upwelling clear-sky short- } \\
\text { wave radiation }\end{array}$ & Monthly, $3 \mathrm{~h}$ \\
\hline tauu & $\begin{array}{l}\text { Surface downward eastward wind } \\
\text { stress }\end{array}$ & thly \\
\hline tauv & $\begin{array}{l}\text { Surface downward northward wind } \\
\text { stress }\end{array}$ & Monthly \\
\hline hfss & Surface upward sensible heat flux & Monthly, $3 \mathrm{~h}$ \\
\hline hfls & vard latent heat flux & Monthly, $3 \mathrm{~h}$ \\
\hline $\mathrm{pr}$ & Precipitation & Monthly, daily, $3 \mathrm{~h}$ \\
\hline evspsbl & Evaporation & Monthly \\
\hline ts & Surface skin temperat & Monthly \\
\hline tas & Near-surface air temperature & Monthly, daily, $3 \mathrm{~h}$ \\
\hline tasmax & $\begin{array}{l}\text { Daily maximum near-surface air } \\
\text { temperature }\end{array}$ & Monthly, daily \\
\hline tasmin & $\begin{array}{l}\text { Daily minimum near-surface air } \\
\text { temperature }\end{array}$ & Monthly, daily \\
\hline uas & Eastward near-surface wind & Monthly, $3 \mathrm{~h}$ \\
\hline vas & Northward near-surface wind & Monthly, $3 \mathrm{~h}$ \\
\hline sfcWind & Near-surface wind speed & Monthly \\
\hline huss & Near-surface specific humidity & Monthly, daily, $3 \mathrm{~h}$ \\
\hline hurs & Near-surface relative humidity & Monthly, daily \\
\hline clt & Total cloud fraction & Monthly, $3 \mathrm{~h}$ \\
\hline ps & Surface air pressure & Monthly, 3 h, 6 h \\
\hline psl & pressure & Monthly, daily \\
\hline snc & Snow area fraction & Monthly, $3 \mathrm{~h}$ \\
\hline ta & Air temperature at model level & Monthly, 6 h \\
\hline ua & Eastward wind at model level & Monthly, $6 \mathrm{~h}$ \\
\hline va & Northward wind at model level & Monthly, $6 \mathrm{~h}$ \\
\hline hus & Specific humidity at model level & Monthly, $6 \mathrm{~h}$ \\
\hline hur & Relative humidity at model level & Monthly \\
\hline $\mathrm{zg}$ & Geopotential height at model level & Monthly \\
\hline
\end{tabular}

the observation.

The simulation of the Madden-Julian Oscillation (MJO) is of interest in current climate models and has remained a great challenge in recent years (Jiang et al., 2015). Here, we present the model skill in capturing the MJO based on daily precipitation and $850 \mathrm{hPa}$ winds. The observed daily precipitation from GPCP (Huffman et al., 2001) and the wind field from ERA-Interim (Dee et al., 2011) are used as reference observations. Using a 20-100-day band-filtered component, we analyzed the zonal propagation of precipitation (colors) and $850-\mathrm{hPa}$ zonal winds (contours) against precipitation in an Indian Ocean reference region $\left(10^{\circ} \mathrm{S}-5^{\circ} \mathrm{N}, 75^{\circ}-100^{\circ} \mathrm{E}\right)$ for boreal winter (Fig. 2). Here, winter is defined from November to April of the following year, following Waliser et al. (2009). Compared with the observations, the dominant feature of MJO eastward propagations (from the Indian Ocean via the western Pacific to the International Date Line) can be simulated well in both precipitation and $850 \mathrm{hPa}$ winds in the AMIP simulation. The quadrature relationship between precipitation and the $850 \mathrm{hPa}$ zonal winds (U850) is reproduced well over the Indian Ocean and western Pacific Ocean in the simulation. Meanwhile, the phase speed is nearly $4-5 \mathrm{~m} \mathrm{~s}^{-1}$, and the lag of the wind anomaly behind precipitation is approximately 5-7 days in the simulation, which is also similar to the result observed in Waliser et al. (2009). Compared with

\section{(a) TRMM \& ERA-interim}

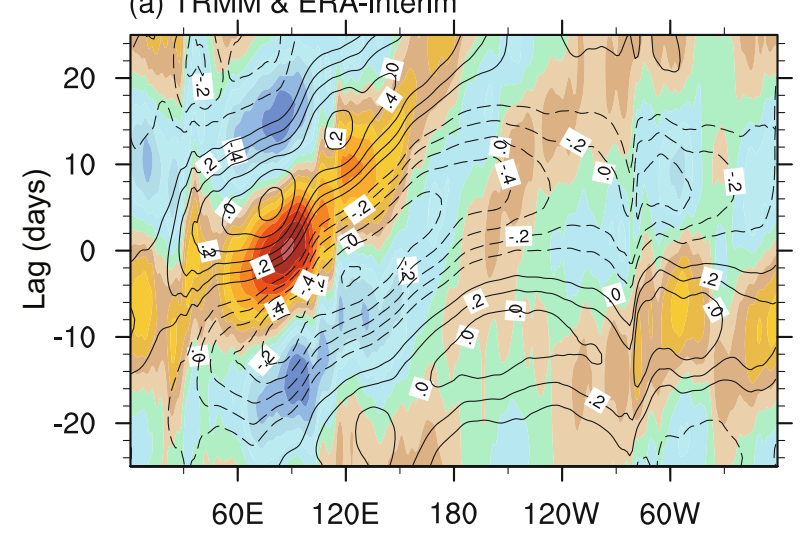

(b) FGOALS-f3-L AMIP

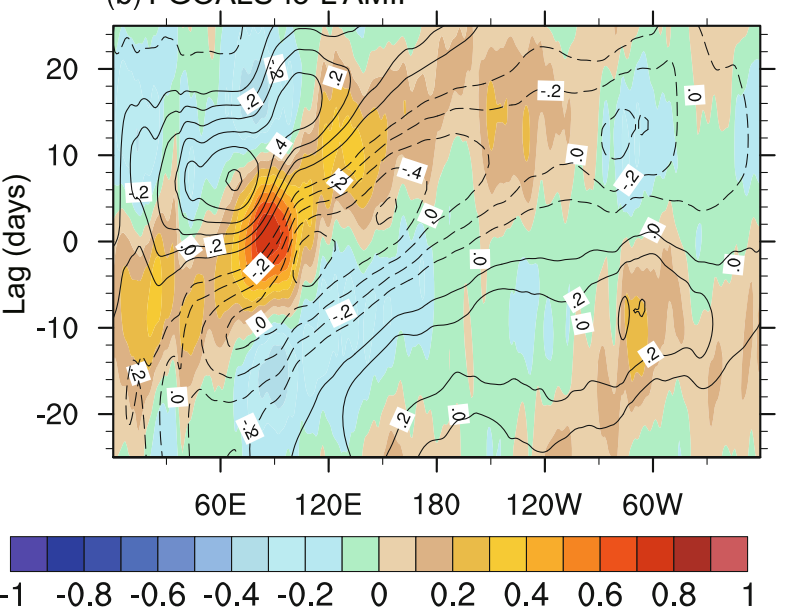

Fig. 2. November-April lag-longitude diagram of the $10^{\circ} \mathrm{S}-$ $10^{\circ} \mathrm{N}$ intraseasonal precipitation anomalies (colors) and intraseasonal 850-hPa zonal wind anomalies (contours) correlated with intraseasonal precipitation over the Indian Ocean reference region $\left(10^{\circ} \mathrm{S}-5^{\circ} \mathrm{N}, 75^{\circ}-100^{\circ} \mathrm{E}\right)$ for (a) observations and (b) the mean of amip r1i1p1f1, r2i1p1f1, and r3i1p1f1. 
the previous version of FAMIL (Yang et al., 2012), the MJO simulation is substantially improved. Small weaknesses are also identified. The propagation of precipitation is increased by two to three days compared to the observation reaching the date line. The rainfall amplitude associated with the MJO is also slightly weaker than in the observation.

Tropical cyclones (TCs), as one of the most drastic phenomena in the world, have considerable impacts on human life. TC forecasting is still a challenge in that most models are unable to predict the tracks very well (Xiang et al., 2015). We evaluate the simulations of TC tracks in AMIP rli1p1f1 based on the six-hourly datasets in Fig. 3. The observed TC tracks (Fig. 3a) are derived from the International Best Track Archive for Climate Stewardship (IBTrACS) (version v03r09) dataset (Knapp et al., 2010), which shows that TCs are active in subtropical oceans in both hemispheres, except for the southeastern Pacific Ocean and the southern Atlantic Ocean. TCs were classified into seven categories according to the Saffir-Simpson (SS) scale (Simpson and Saffir, 1974), as shown in different colors in Fig. 3. Based on the six-hourly dataset in AMIP r1i1p1f1, the model could successfully capture the global pattern of the tropical storm (TS) tracks (green lines) (Fig. 3b), except that the model underestimates the TS tracks in the eastern Pacific and northern Atlantic Ocean while producing unrealistic tracks over the southern Atlantic. Category 4 and 5 TCs are also underestimated in the model. These results suggest that the model can capture TC tracks, but the intensity is slightly weaker, and the six-hourly datasets are quite reliable for conducting TC research.

Realistic reproduction of historical extreme precipitation has been challenging for both reanalysis and GCM simula-

\section{(a) IBTrACS}

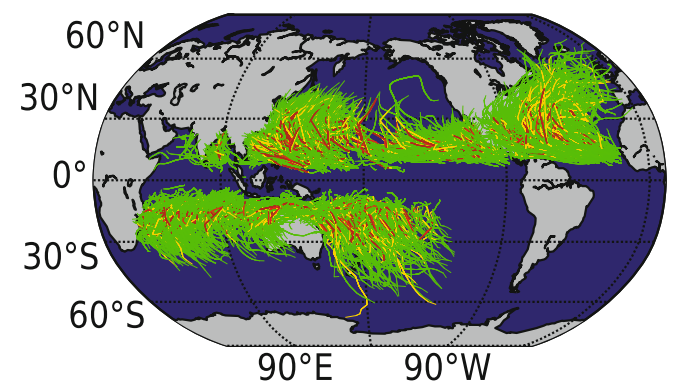

tions (He et al., 2019). We evaluate the simulations of extreme precipitation over the tropics $\left(20^{\circ} \mathrm{S}-20^{\circ} \mathrm{N}\right)$ in the AMIP r1i1p1f1 daily outputs. Tropical Rainfall Measuring Mission (TRMM)-3B42 data are used as reference observations (Huffman et al., 2007) and were interpolated at the same resolution as AMIP r1i1p1f1 by the nearest-neighbor interpolation method (Accadia et al., 2003). The frequency of precipitation was plotted against the daily precipitation rate at a $1 \mathrm{~mm} \mathrm{~d}^{-1}$ interval. For the extreme precipitation, the frequency-intensity distribution (Fig. 4) in CAS FGOALS$\mathrm{f} 3-\mathrm{L}$ is extended up to $350 \mathrm{~mm} \mathrm{~d}^{-1}$, which shows that similar characteristics manifested in the TRMM data. The frequency-intensity distribution in the model is also comparable under $50 \mathrm{~mm} \mathrm{~d}^{-1}$ with the TRMM data, while it is slightly overestimated above $50 \mathrm{~mm} \mathrm{~d}^{-1}$. These results suggest that the model can simulate enough extreme precipitation over tropical regions, but the frequency of extreme precipitation is slightly overestimated.

\section{Usage notes}

The original atmospheric model grid is in the cube-sphere grid system with the resolution of $\mathrm{C} 96$, which has six tiles and is irregular in the horizonal direction. We merge and interpolate the tiles to a nominal resolution of $1^{\circ}$ on a global latitude-longitude grid scaled by one-order conservation interpolation, as required by CMIP6, for public use. For the users who want to calculate pressure at model layers, we provide hybrid level " $A$ " coefficient at mid-point levels (hyam), hybrid level "B" coefficient at mid-point levels (hybm), hybrid level "A" coefficient on the interfaces (hyai), and hybrid level "B" coefficient on the interfaces (hybi) in Table 4. Then,
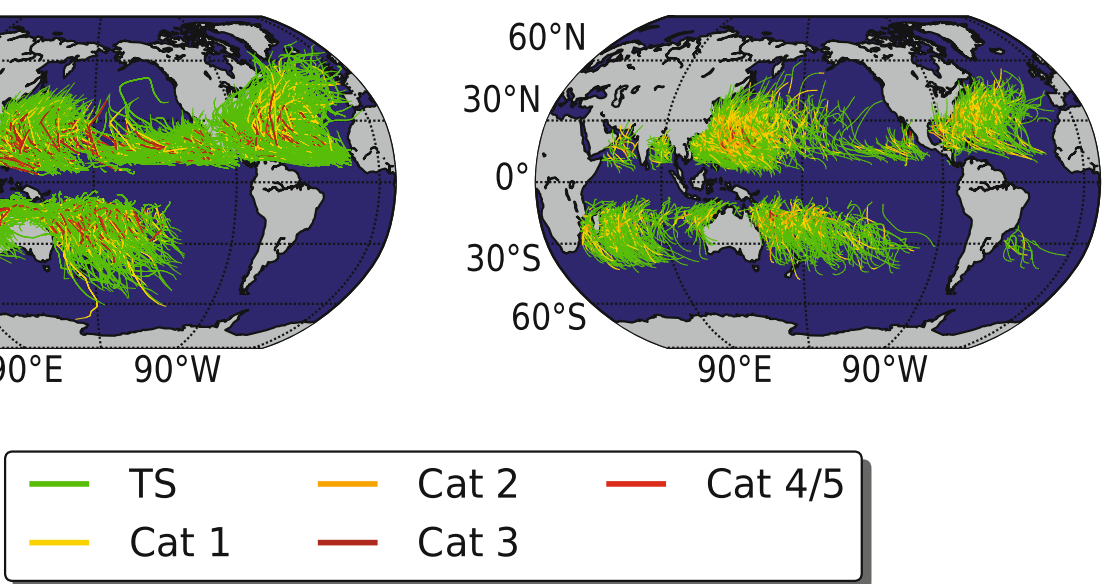

Fig. 3. TC tracks (lines) and intensities (colors) (a) from a 36-year segment (1979-2014) of IBTrACS data and (b) from the simulation of AMIP r1i1p1f1, which are detected by using an objective feature-tracking approach at the C96 resolution (approximately $100 \mathrm{~km}$ ) from 1979-2014. Only those TCs with a lifetime exceeding three days are shown. The TCs in both the simulation of AMIP r1i1p1f1 and the observation of IBTrACS are grouped into seven categories in accordance with the modified Saffir-Simpson scale, but only TCs stronger than TSs are shown. 


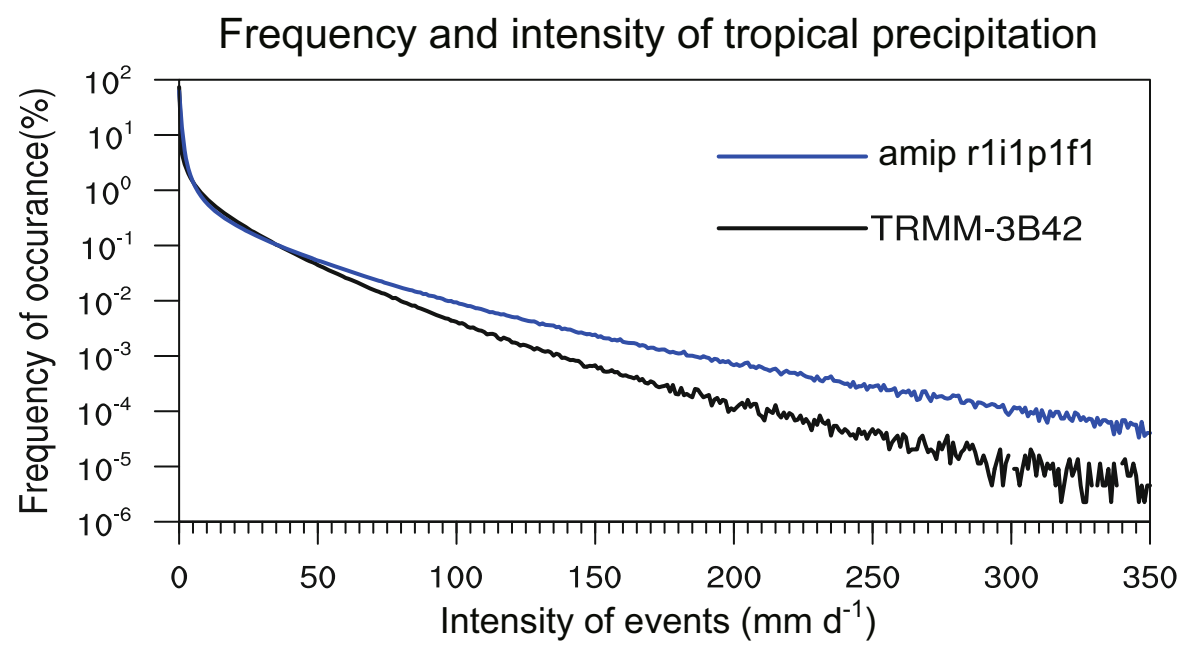

Fig. 4. Annual rainfall frequency-intensity distribution in TRMM-3B42 (black line) and CAS FGOALS-f3-L AMIP r1i1p1f1 (blue line) from 1998-2010. The domain is the tropical region $\left(20^{\circ} \mathrm{S}-20^{\circ} \mathrm{N}\right)$.

Table 4. Hybrid level coefficients of CAS FGOALS-f3-L atmospheric component.

\begin{tabular}{|c|c|c|c|c|}
\hline $\begin{array}{l}\text { Layers } \\
\text { (from top } \\
\text { to bottom) }\end{array}$ & hyam & hybm & hyai & hybi \\
\hline 1 & 0.0025 & 0 & 0.001 & 0 \\
\hline 2 & 0.00609301 & 0 & 0.004 & 0 \\
\hline 3 & 0.01098744 & 0 & 0.00818602 & 0 \\
\hline 4 & 0.01735341 & 0 & 0.01378886 & 0 \\
\hline 5 & 0.02537718 & 0 & 0.02091795 & 0 \\
\hline 6 & 0.03552715 & 0 & 0.02983641 & 0 \\
\hline 7 & 0.04850506 & 0 & 0.0412179 & 0 \\
\hline 8 & 0.06499507 & 0 & 0.05579222 & 0 \\
\hline 9 & 0.08562309 & 0 & 0.07419793 & 0 \\
\hline 10 & 0.1110058 & 0 & 0.09704826 & 0 \\
\hline 11 & 0.141758 & 0 & 0.1249634 & 0 \\
\hline 12 & 0.1784744 & 0 & 0.1585526 & 0 \\
\hline 13 & 0.2217118 & 0 & 0.1983963 & 0 \\
\hline 14 & 0.2633992 & 0.008555 & 0.2450273 & 0 \\
\hline 15 & 0.2885119 & 0.04095 & 0.281771 & 0.01711 \\
\hline 16 & 0.2927081 & 0.101045 & 0.2952529 & 0.06479 \\
\hline 17 & 0.2807384 & 0.182115 & 0.2901634 & 0.1373 \\
\hline 18 & 0.2576872 & 0.275545 & 0.2713133 & 0.22693 \\
\hline 19 & 0.2286608 & 0.37237 & 0.2440611 & 0.32416 \\
\hline 20 & 0.1977362 & 0.465815 & 0.2132605 & 0.42058 \\
\hline 21 & 0.1674816 & 0.55215 & 0.1822118 & 0.51105 \\
\hline 22 & 0.1392841 & 0.629765 & 0.1527515 & 0.59325 \\
\hline 23 & 0.1138155 & 0.698195 & 0.1258168 & 0.66628 \\
\hline 24 & 0.09131663 & 0.757635 & 0.1018143 & 0.73011 \\
\hline 25 & 0.07176384 & 0.808665 & 0.08081898 & 0.78516 \\
\hline 26 & 0.0549811 & 0.85207 & 0.0627087 & 0.83217 \\
\hline 27 & 0.04071371 & 0.888715 & 0.0472535 & 0.87197 \\
\hline 28 & 0.02867573 & 0.919475 & 0.03417392 & 0.90546 \\
\hline 29 & 0.01857925 & 0.94517 & 0.02317755 & 0.93349 \\
\hline 30 & 0.01015295 & 0.966545 & 0.01398095 & 0.95685 \\
\hline 31 & 0.00316248 & 0.984235 & 0.00632495 & 0.97624 \\
\hline 32 & 0 & 0.996115 & 0 & 0.99223 \\
\hline 33 & & & 0 & 1 \\
\hline
\end{tabular}

the pressures can be derived from the following expression:

$$
P_{(i, j, k)}=A_{k} P_{0}+B_{k} P s_{(i, j)},
$$

where $P_{(i, j, k)}$ denotes the desired pressure at the model midpoint level or interfaces, $A_{k}$ denotes hyam or hyai, $P_{0}$ denotes $1000 \mathrm{hPa}, B_{k}$ denotes hybm, hybi, and $P s_{(i, j)}$ denotes the surface pressure. The $(i, j, k)$ denotes the longitude index, latitude index, and vertical layer index, respectively.

The format of datasets is the version 4 of Network Common Data Form (NetCDF), which can be easily read and written by professional common software such as Climate Data Operators (https://www.unidata.ucar.edu/software/netcdf/ workshops/2012/third_party/CDO.html), NetCDF Operator (http://nco.sourceforge.net), NCAR Command Language (http://www.ncl.ucar.edu), and Python (https://www.python. org).

Acknowledgements. The research presented in this paper was jointly funded by the National Key Research and development Program of China (Grant No. 2017YFA0604004), the National Natural Science Foundation of China (Grant Nos. 91737306, U1811464, 41530426, 91837101, 41730963, and 91637312).

\section{Data availability statement}

The data that support the findings of this study are available from https://esgf-node.llnl.gov/projects/cmip6/.

\section{Disclosure statement}

No potential conflict of interest was reported by the authors.

Open Access This article is distributed under the terms of the Creative Commons Attribution License which permits any use, distribution, and reproduction in any medium, provided the original 
author(s) and the source are credited.

\section{REFERENCES}

Accadia, C., S. Mariani, M. Casaioli, A. Lavagnini, and A. Speranza, 2003: Sensitivity of precipitation forecast skill scores to bilinear interpolation and a simple nearest-neighbor average method on high-resolution verification grids. Wea. Forecasting, 18, 918-932, https://doi.org/10.1175/1520-0434(2003) $018<0918$ :SOPFSS $>2.0 . \mathrm{CO} ; 2$.

Adler, R. F., and Coauthors, 2003: The version-2 global precipitation climatology project (GPCP) monthly precipitation analysis (1979-present). Journal of Hydrometeorology, 4, 1147-1167, https://doi.org/10.1175/1525-7541(2003)004 $<1147$ :TVGPCP $>2.0$. CO; 2 .

Bao, Q., G. X. Wu, Y. M. Liu, J. Yang, Z. Z. Wang, and T. J. Zhou, 2010: An introduction to the coupled model FGOALS1.1$s$ and its performance in East Asia. Adv. Atmos. Sci., 27(5), 1131-1142, https://doi.org/10.1007/s00376-010-9177-1.

Bao, Q., and Coauthors, 2013: The flexible global oceanatmosphere-land system model, spectral version 2: FGOALSs2. Adv. Atmos. Sci., 30(3), 561-576, https://doi.org/10.1007/ s00376-012-2113-9.

Bao, Q., X. F. Wu, J. X. Li, L. Wang, B. He, X. C. Wang, Y. M. Liu, and G. X. Wu, 2019: Outlook for El Niño and the Indian Ocean Dipole in autumn-winter 2018-2019. Chinese Science Bulletin, 64, 73-78, https://doi.org/10.1360/N972018-00913. (in Chinese)

Bretherton, C. S., and S. Park, 2009: A new moist turbulence parameterization in the community atmosphere model. $J$. Climate, 22(12), 3422-3448, https://doi.org/10.1175/2008 jcli2556.1.

Clough, S. A., M. W. Shephard, E. J. Mlawer, J. S. Delamere, M. J. Iacono, K. Cady-Pereira, S. Boukabara, and P. D. Brown, 2005: Atmospheric radiative transfer modeling: A summary of the AER codes. Journal of Quantitative Spectroscopy and Radiative Transfer, 91(2), 233-244, https://doi. org/10.1016/j.jqsrt.2004.05.058.

Dee, D. P., and Coauthors, 2011: The ERA-interim reanalysis: Configuration and performance of the data assimilation system. Quart. J. Roy. Meteor. Soc., 137, 553-597, https://doi. org/10.1002/qj.828.

Edwards, J. M., and A. Slingo, 1996: Studies with a flexible new radiation code. I: Choosing a configuration for a large-scale model. Quart. J. Roy. Meteor. Soc., 122, 689-719, https:// doi.org/10.1002/qj.49712253107.

Eyring, V., S. Bony, G. A. Meehl, C. A. Senior, B. Stevens, R. J. Stouffer, and K. E. Taylor, 2016: Overview of the coupled model intercomparison project phase 6 (CMIP6) experimental design and organization. Geoscientific Model Development, 9, 1937-1958, https://doi.org/10.5194/gmd-9-19372016.

Gates, W. L., 1992: AMIP: The atmospheric model intercomparison project. Bull. Amer. Meteor. Soc., 73, 1962-1970, https:// doi.org/10.1175/1520-0477(1992)073<1962:ATAMIP>2.0. $\mathrm{CO} ; 2$.

Gates, W. L., and Coauthors, 1999: An overview of the results of the atmospheric model intercomparison project (AMIP I). Bull. Amer. Meteor. Soc., 80, 29-56. https://doi.org/10.1175/ 1520-0477(1999)080<0029:AOOTRO > 2.0.CO;2.

Harris, L. M., and S.-J. Lin, 2014: Global-to-regional nested grid climate simulations in the GFDL high resolution atmospheric model. J. Climate, 27(13), 4890-4910, https://doi.org/ 10.1175/JCLI-D-13-00596.1.

He, S. C., J. Yang, Q. Bao, L. Wang, and B. Wang, 2019: Fidelity of the observational/reanalysis datasets and global climate models in representation of extreme precipitation in East China. J. Climate, 32(1), 195-212, https://doi.org/10.1175/ JCLI-D-18-0104.1.

Holtslag, A. A. M., and B. A. Boville, 1993: Local versus nonlocal boundary-layer diffusion in a global climate model. J. Climate, 6, 1825-1842, https://doi.org/10.1175/1520-0442 (1993)006<1825:LVNBLD>2.0.CO;2.

Huffman, G. J., R. F. Adler, M. M. Morrissey, D. T. Bolvin, S. Curtis, R. Joyce, B. McGavock, and J. Susskind, 2001: Global precipitation at one-degree daily resolution from multisatellite observations. Journal of Hydrometeorology, 2, 36-50, https://doi.org/10.1175/1525-7541(2001)002<0036: GPAODD $>2.0 . \mathrm{CO} ; 2$.

Huffman, G. J., and Coauthors, 2007: The TRMM multisatellite precipitation analysis (TMPA): Quasi-global, multiyear, combined-sensor precipitation estimates at fine scales. Journal of Hydrometeorology, 8, 38-55, https://doi.org/10.1175/ JHM560.1.

Hunke, E. C., and W. H. Lipscomb, 2010: CICE: The Los Alamos Sea ice model documentation and software user's manual version 4.1. Tech. Rep. LA-CC-06-012, 675 pp.

Hurtt, G. C., and Coauthors, 2011: Harmonization of land-use scenarios for the period 1500-2100: 600 years of global gridded annual land-use transitions, wood harvest, and resulting secondary lands. Climatic change, 109(1-2), 117, https://doi.org/ 10.1007/s10584-011-0153-2.

Jiang, X., and Coauthors, 2015: Vertical structure and physical processes of the Madden-Julian oscillation: Exploring key model physics in climate simulations. J. Geophys. Res., 120, 4718 4748, https://doi.org/10.1002/2014JD022375.

Knapp, K. R., M. C. Kruk, D. H. Levinson, H. J. Diamond, and C. J. Neumann, 2010: The international best track archive for climate stewardship (IBTrACS): Unifying tropical cyclone data. Bull. Amer. Meteor. Soc., 91(3), 363-376, https:// doi.org/10.1175/2009BAMS2755.1.

Lamarque, J.-F., and Coauthors, 2012: CAM-chem: Description and evaluation of interactive atmospheric chemistry in the community earth system model. Geoscientific Model Development, 5(2), 369-411, https://doi.org/10.5194/gmd-5-3692012.

Li, J. X., Q. Bao, Y. M. Liu, G. X. Wu, L. Wang, B. He, X. C. Wang, and J. D. Li, 2019: Evaluation of FAMIL2 in simulating the climatology and seasonal-to-interannual variability of tropical cyclone characteristics. Journal of Advances in Modeling Earth Systems, https://doi.org/10.1029/2018MS001506.

Lin, S.-J., 2004: A "vertically Lagrangian" finite-volume dynamical core for global models. Mon. Wea. Rev., 132(10), 2293 2307, https://doi.org/10.1175/1520-0493 (2004) $132<2293$ : AVLFDC $>2.0 . C O ; 2$.

Lin, Y.-L., R. D. Farley, and H. D. Orville, 1983: Bulk parameterization of the snow field in a cloud model. J. Climate Appl. Meteor., 22(6), 1065-1092, https://doi.org/10.1175/1520-0450 (1983)022<1065:BPOTSF>2.0.CO;2.

Liu, H. L., P. F. Lin, Y. Q. Yu, and X. H. Zhang, 2012: The baseline evaluation of LASG/IAP climate system ocean model (LICOM) version 2. Acta Meteorologica Sinica, 26(3), 318-329, https://doi.org/10.1007/s13351-012-0305-y. 
Matthes, K., and Coauthors, 2017: Solar forcing for CMIP6 (v3.2). Geoscientific Model Development, 10(6), 2247-2302, https:// doi.org/10.5194/gmd-10-2247-2017.

Meinshausen, M., and Coauthors, 2017: Historical greenhouse gas concentrations for climate modelling (CMIP6). Geoscientific Model Development, 10, 2057-2116, https://doi.org/10.5194/ gmd-10-2057-2017.

Nordeng, T. E., 1994: Extended versions of the convective parameterization scheme at ECMWF and their impact on the mean and transient activity of the model in the tropics. ECMWF Technical Memo. 206, 41 pp.

Oleson, K. W., and Coauthors, 2010: Technical description of version 4.0 of the community land model (CLM). NCAR/TN478 + STR, 173 pp, https://doi.org/10.5065/D6FB50WZ.

Palmer, T. N., G. J. Shutts, and R. Swinbank, 1986: Alleviation of a systematic westerly bias in general circulation and numerical weather prediction models through an orographic gravity wave drag parametrization. Quart. J. Roy. Meteor. Soc., 112(474), 1001-1039, https://doi.org/10.1002/qj. 49711247406.

Putman, W. M., and S.-J. Lin, 2007: Finite-volume transport on various cubed-sphere grids. J. Comput. Phys., 227(1), 55-78, https://doi.org/10.1016/j.jcp.2007.07.022.

Simpson, R. H., and H. Saffir, 1974: The hurricane disasterpotential scale. Weatherwise, 27(4), 169-186, https://doi.org/ 10.1080/00431672.1974.9931702.

Sun, Z. A., and L. Rikus, 1999: Improved application of exponential sum fitting transmissions to inhomogeneous atmosphere. J. Geophys. Res., 104, 6291-6303, https://doi.org/10.1029/ 1998JD200095.

Tiedtke, M., 1989: A comprehensive mass flux scheme for cumu- lus parameterization in large-scale models. Mon. Wea. Rev., 117, 1779-1800, https://doi.org/10.1175/1520-0493(1989) $117<1779$ :ACMFSF $>2.0 . \mathrm{CO} ; 2$.

Waliser, D., and Coauthors, 2009: MJO simulation diagnostics. J. Climate, 22, 3006-3030, https://doi.org/10.1175/2008 JCLI2731.1.

Wang, X. C., and M. H. Zhang, 2014: Vertical velocity in shallow convection for different plume types. Journal of Advances in Modeling Earth Systems, 6(2), 478-489, https://doi.org/ 10.1002/2014MS000318.

Wu, G. X., H. Liu, Y. C. Zhao, and W. P. Li, 1996: A ninelayer atmospheric general circulation model and its performance. Adv. Atmos. Sci., 13(1), 1-18, https://doi.org/10.1007/ bf02657024.

Xiang, B. Q., and Coauthors, 2015: Beyond weather time-scale prediction for hurricane sandy and super typhoon Haiyan in a global climate model. Mon. Wea. Rev., 143(2), 524-535, https://doi.org/10.1175/MWR-D-14-00227.1.

Xu, K. M., and D. A. Randall, 1996: A semiempirical cloudiness parameterization for use in climate models. J. Atmos. Sci., 53(21), 3084-3102, https://doi.org/10.1175/1520-0469 (1996)053<3084:ASCPFU>2.0.CO;2.

Yang, J., Q. Bao, X. C. Wang, and T. J. Zhou, 2012: The tropical intraseasonal oscillation in SAMIL coupled and uncoupled general circulation models. Adv. Atmos. Sci., 29(3), 529-543, https://doi.org/10.1007/s00376-011-1087-3.

Zhou, L. J., and Coauthors, 2015: Global energy and water balance: Characteristics from finite-volume Atmospheric Model of the IAP/LASG (FAMIL1). Journal of Advances in Modeling Earth Systems, 7(1), 1-20, https://doi.org/10.1002/2014 ms000349. 